\title{
Environmental Governance in Power Plant Project: A Case Study from Thailand
}

\author{
Chutarat Chompunth \\ National Institute of Development Administration, Thailand
}

\begin{abstract}
.
In Thailand, energy and power plant project issues have been one of the key topics circulating in public attention. The disagreement and conflict from the operation of the power plant become worsened. Thus, the power plant is required to comply with all terms and conditions to meet all legal and environmental compliance. This research has the objective to study the operation of The BLCP Power Plant in accordance with the principle of environmental governance, as well as the success factors and problems or obstacles in order to promote and support the operation of the BLCP Power Plant in accordance with good environmental governance. This research is a qualitative research. Data were collected through in-depth interviews with stakeholders and the study of relevant documents. The main application of The Access Initiative (TAI) was applied as the indicators focused on the evaluation of the "process" which consists of 3 categories: access to information, participation in the decision-making process and access to justice. The study showed that the operation of The BLCP Power Plant is carried out in accordance with the principles of environmental governance and legal operation. This consists of the disseminating process of information through various media, establishment of a forum to hear the opinions and concerns of local people to encourage them to participate in the community's environmental management. There is also a compensation process that provides aides, in cases where people are affected. The suggestion from this study is that power plants should provide knowledge and understanding within the community. There should be clear procedures for remedying those affected by the operation of the power plant. Also, the people must recognise their rights and duty, widen their perspective in order to achieve sustainable development in Thai society.
\end{abstract}

Keywords: Environmental Governance, Power Plant Project, Public Participation, Conflict 


\section{Introduction}

The development of the power plant project may affect the people in that area due to the operation of the power plant project. From the incident and the past complaints, one of the major causes of the problem is that the implementation of the project is not in line with the principle of good governance, especially the lack of public participation process, which is an important step [1]. The people lack awareness or information about the implementation and safety measures, including the response to the emerging anxiety and solutions that do not meet the needs of the people. This affects the image and the public trust of the power plants [2].

The BLCP Power Plant is a large power plant development project which is located in Map Ta Phut Industrial Estate near the community. The operation began in 2006. The power plant was well designed and furnished with all modern tools under recognised technology. The fuel source is bituminous coal imported from Australia and Indonesia. Main concern is given that the plant must be complied with all legal and environmental requirements in order to get acceptance from all nearby and affected communities. There was few opposition and resistance to the construction and operation of the power plant. Also, there were no violent protests like the Mae Moh Coal-fired Power Plant Project, Khao Hin Sorn coal-fired power plant and the Nong Saeng Power Plant Project, etc. Undoubted, the concept of Environmental Governance refers to the management of natural resources and the environment where the public can access the information, engage in the decision making of policy, strategies, plans, projects, and activities that will affect natural resources and the environment must be transparent, wellprepared, accountable and fair [[3], [4]].If the power plants operate in accordance with good environmental governance, they will result in a sustainable community living.

For this research, the intention in to study the principle of Environmental Governance: A Case Study of The BLCP Power Plant by using The Access Initiative (TAI), an international network of environmental civil society organizations. The TAI indicators is a qualitative indicator that consists of three categories to evaluate; the "process" of accessing information, participation in the decision-making process and access to justice [5]. This research aims to study the operation of the BLCP Power Plant in accordance with environmental governance and to provide guidance for promoting and supporting the implementation of Environmental Governance Principles of the BLCP Power Plant. Theoretical concepts can be framed in the context of environmental governance research as shown in Figure 1 


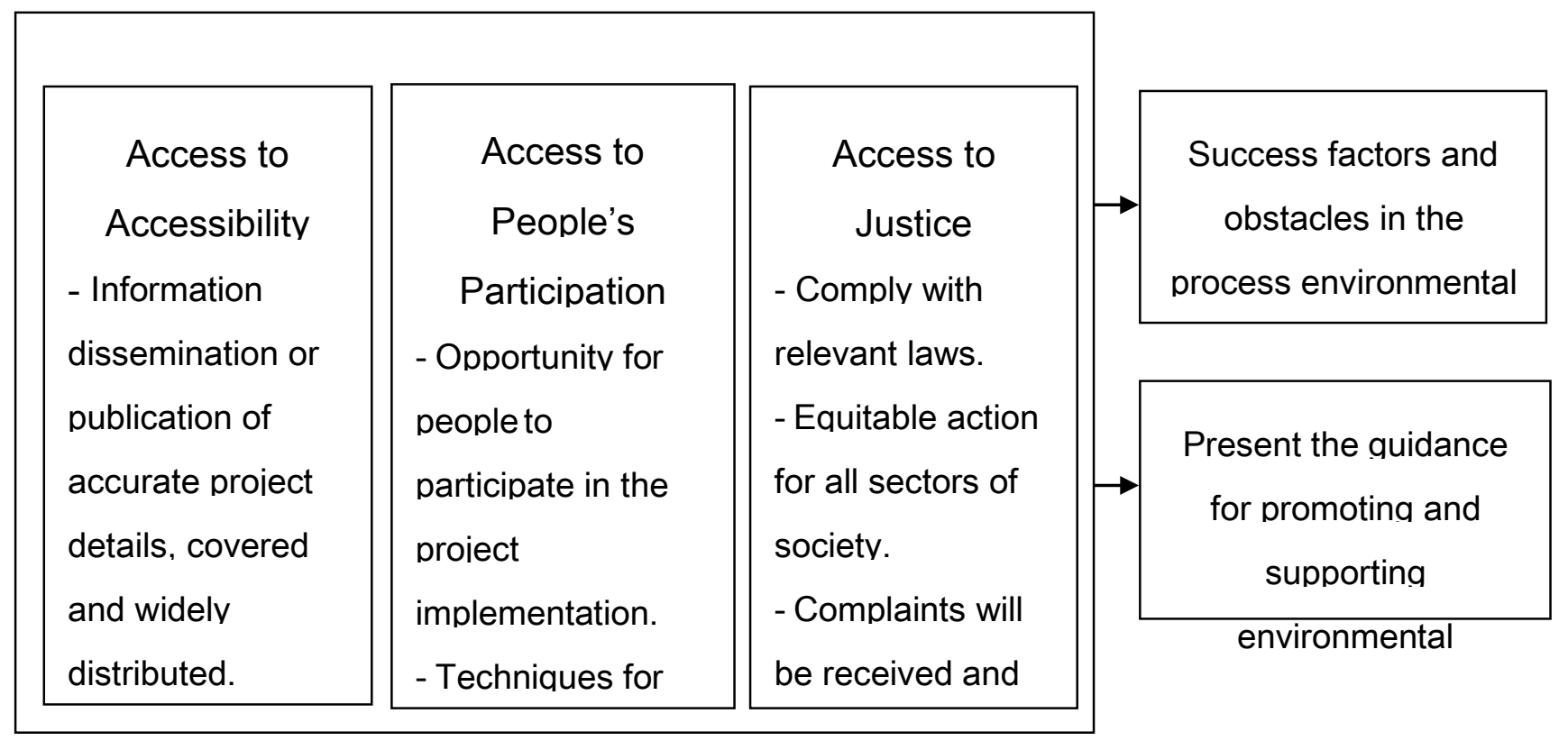

Environmental Governance

\section{Research Methodology}

Figure 1 Theoretical framework

This research is qualitative research. Primary data were collected through in-depth interviews with stakeholders. The interview instrument was an open-ended questionnaire designed specifically for each sample group. The questionnaires are separated into 6 categories; central government, local government agencies, academics from various agencies and non-profit organizations, community leaders and public interviews.

The interview questions were divided into 3 parts: Part 1: Basic information of the survey taker. Part 2: Implementation of the environmental governance which was divided into 2.1

Access and information of the people. 2.2 Public participation in the decision making process and 2.3 Access to justice and section Part 3. Recommendations. Secondly, secondary data were obtained from the review of academic literature, academic papers and article. The researcher will take the primary and secondary data to be validated, analysed and synthesized to obtain information according to the objectives of the research. The descriptive analysis was applied to summarize the content, comments and reviews. Then, present the issues set out in each interview topic to ensure the consistence of the study with the objectives of the research and then proposed the conceptual framework. This is to summarize the study on various issues and to obtain the most relevant and complete information. The method of in-depth interviews was used to collect data while Purposive Selection method was applied to the interview of project owners, relevant government agencies, and academic from various agencies, non-profit organizations and affected groups of people and community leaders around the project area. This research applied Snowball techniques to selected 29 interviewees. Details are as follows.

1) The owner of the project 4 person 2) The community leaders in the $5 \mathrm{~km}$ radius of the BLCP Power Plant (Informal and informal) (5 persons) 3) People affected by the BLCP Power Plant within a $5 \mathrm{~km}$ radius of the Power Plant (10 persons) 4) Local government officials or 
staff members (2 person) 5) Government officials or government officials (5 person) 6) Academicians from various agencies and NGOs / NGOs (3 person)

\section{Results and Discussion}

The study indicated that the operating practices of the BLCP Power Plant were based on concept of environmental governance practices are as followed.

(1) Access to information and perception consists of:

1) The publicity information is accurate, comprehensive and thorough for the public to understand in the same direction. However, the information provided by The BLCP Power Plant does not cover the needs of the people and community leaders. Furthermore, the public relations of the BLCP Power Plant are showcasing only the activities that the power plant has undertaken with the community, such as beautiful canals, clear water, crabs etc. They also publicizing the warning of noise during the production process which may have a significant impact on the community. The $1^{\text {st }}$ member of the community said, "There were announcement within the community on the community radio about a lot of noise caused by the soot blowing process." The $2^{\text {nd }}$ official said that "There are news dissemination through the magazine of the power plant and community radio" which are methods that does not yet covered the 5-kilometer radius around the power plant. The detailed information of the project, such as capacity, technology used in the production process, safety measures and prevention of the impact on the environment and the community were not published to the public as much as it should have. The $2^{\text {nd }}$ community leader said, "We had to contact the power plant by ourselves for information or self-research from the internet." The $3^{\text {rd }}$ associated member from the non-profit organization says, "The power plant should survey the area to interact with the locals more". In addition, the 6th government officials said, "There must be many level of communications with the people. It should be divided into groups using public relations media, such as infographic for the public, as well as accurate information".

2) Channels or opportunities for people to access information. The $1^{\text {st }}$ power plant official said, "The power plant has an open house project for people to visit the production process and exchange knowledge about the project implementation of the power plant". In addition, information is disseminated via various channels as the $2^{\text {nd }}$ power plant official stated, "There are many ways, such as journal newsletter, local media and through the community leader and it is a good idea to use the media and public relations tackles". In order to ensure effective public relations, power plants should provide clear access to information and a coordinating center for coordination and information to provide information for the public at all times and to discuss or exchange information. This will achieve the satisfactory of the public.

3) Consultation or exchange of ideas. The $2^{\text {nd }}$ power plant official said, "The power plant has done survey in the community to provide insight into the operation of the power plant. The goal is to listen and recognize the needs and 
problems of the community, "and the $2^{\text {nd }}$ community leader said, "The power plants and the public have two-way communication, as seen in community organization council meetings held every month. The power plant has sent staff to attend the meeting to hear from the villagers which the power plant will report on its performance in solving the problems, "which is in accordance to the consultation or exchange of ideas concept. Therefore, there should be a two-way communication in the process of consultation and exchange of information. The power plant should also disclose performance data, such as environmental quality monitoring reports.

(2) Public participation in decision making consists of:

1) Opportunity for people to participate in the decision-making process. The first power plant official said, "The power plant has a public hearing and community activities" and the $2^{\text {nd }}$ power plant official said that "We have provided the opportunity for people to propose and create their own environmental activities for them to participate in the activities with the power plant." However, the process of listening to the opinions of the people are not thorough enough and do not cover all areas. The $2^{\text {nd }}$ academics from associated agencies and non-profit organization said, "The venue for the meeting is too far. No meetings were held in the district of the power plant". Some people did not know the information and publicity of the power plant. The Local government officials said, "The project or activity proposed by the power plant was not in accordance with the view of the locals". Therefore, the power plant should have a clear plan or guidelines for social and environmental activities in the community and let the public participate in activities to prevent and alleviate the environmental impact caused by the power plant thoroughly which is consistent with [6]. It is a process in which stakeholders have the opportunity to express their views and exchange Information and comments to seek alternatives and decisions.

2) Techniques or methods used in public participation in decision making. The $2^{\text {nd }}$ power plant official said, "The power plant uses the method of discussion, surveys and public hearing to listen to comments, " which corresponds with the Office of the National Economic and Social Development Board (NESDB) which stated that organizations should use one or more of the following methods; Polls, Consultation and other ways which is assigned by the Office of the Prime Minister. As the 2nd community leader said, "There should be community-level subgroups to get public input which will be proposed in the meeting.". Therefore, the power plant must be transparent, have sufficient time and appropriate consideration of stakeholder needs. In considering the stakeholder around the power plant area, it should cover a radius of $5 \mathrm{~km}$ around the power plant and people outside the affected area, and Abe et al. [7] found that the process which would bring about governance and public participation are the creation of conditions and mechanisms to create participate in appropriate levels that will lead to the development of projects, along with effective environmental care.

3) The information is accurate, complete and clear. The first power plant official said, "The power plant has made accurate and clear disclosures through public 
hearings," and scholars from various agencies and non-profit organizations said that the provided information should be "Information that is true, reliable, and can be explained and easily understood by the public in each group or class " The power plant must have the truth in the participatory process, with clarity of purpose, participation and openness. Also, there should be opportunity for the people to ask questions.

4) Public participation affects decision-making in the operation of power plants. "People's participation in the decision-making process of a power plant as the role of government agencies or state enterprises is that they must listen to the voice of the people in order to make decisions". However, the second community leader said "The power plant has a plan or policy, and the public hearing is just a legal proceeding." The Electricity Generating Authority of Thailand, as a government agency, has adopted the opinion of the people. The application for permission to operate the project is in line with the good governance principle, which is in line with the finding of Paavola [8]. The three main cultures are developing a participatory development, democratic processes and good governance and justice. Also, the implementation of each activity may take a period of time. The $1^{\text {st }}$ power plant officials said, "It's impossible for everyone to be happy, but the power plant will do their best," and the third power plant official said, "We need to build trust to strengthen the community, so that the power plants can live together with the community in a sustainable way.

(3) Access to justice includes:

1) Compliance with the law relating to the operation of the power plant; The first power plant official said, "The power plant complies with the laws governing the operation of power plants with a capacity of 10 megawatts," such as the Environmental Quality Promotion Act 1992. The gaps in the law can be interpreted in many ways, including duplication of law and unclear and non-violent penalties.

2) Fair operation with all sectors. The first power plant official said, "The power plant sees the importance of the community by taking into account the collective interests, the priority of the problem and the impact of the operation of the power plant to benefit the people in the community fairly and accordingly." which corresponds to Tippett et al. [9] concept of justice, that juridical institutions in a society of justice should not benefit a group of people on the costs of others or on the basis of their natural and social foundations. Difference "The power plant does not really meet the needs of the people," said the powerhouse. "The power plants should clarify the reasons for prioritizing and addressing the problem. For the public sector or community leaders, they should know their rights and responsibilities, and take appropriate measures to solve the problem or prevent the impact of the power plant.

3) Responding to the complaint by the first power plant officer, "The power plant has a way to handle complaints through phone calls, Internet community leaders, and complaints boxes at the front of the power plant, as well as complaints through the area of the staff and upon receipt of the complaint." The local government 
agency says, "People will complain through community leaders." In some cases, the complaints are unresponsive from the power plant. Therefore, the power plant should create better understanding of the complaint process for the community. This is in line with Chompunth and Chomphan [6] Ogunlana et al. [10], which refers to the management of a complaint that refers to the process of resolving a complaint with a goal for the issue to be that has been resolved or alleviated.

4) Reimbursement, the first power plant official said, "If it is proven that the people were affected by the operation of the power plant. We will compensate and heal the affected people appropriately." One authority also commented that "remedies are an important element of the proposal for justice. Remedies should act as a mechanism leading to the acceptance of violations and the responsibility of the state for damages". So, academics from various agencies and third non-profit organization agreed that the power plant should have a clear policy on remedies.

For the second aspect, the success factors in implementing the project are the implementation of relevant laws and the knowledge and understanding of electricity generation technologies as well as the safety measures of the power plants to ensure that the power plant can live together with the community in a sustainable manner, with sincerity, policies, plans and activities that people can access. In terms of problems or obstacles, community leaders and the public have a negative attitude towards the power plant, which causes insecurity in the prevention and remedy of environmental impacts that will affect the traditional way of life of the community.

Thirdly, the guidelines for promoting and supporting the implementation of the environmental governance of the BLCP Power Plant include: 1. Guidelines for the promotion and support of the operation of the power plant, the policy is to: (1) Promote the policy of community building around the power plant; (2) Develop an active social responsibility policy to express the (3) Promote compensation/remedial policies and solve urgent problems in the event of an emergency. (4) There should be a policy of getting people in the area to serve as mass media officers so that they can communicate or know the needs and environment in the community. 2. Guidelines for the promotion and support of the operation of the BLCP Power Plant to be in line with the principles of good environmental governance. (1) The creation of the knowledge base with the people and community leaders through a community learning center located in the 5-kilometer radius of the power plant or within a community that may be affected to provide insights into technology, electricity generation, safety measures, and measures to prevent and address environmental impacts [11] (2) Develop the potential of

community leaders in community environmental management. (3) Promote environmental management in the community by sharing with the people, community leaders and local government organizations. (4) Promote knowledge to the people at all levels. (5) It is necessary to build knowledge and understanding for the community to protect themselves and help those around them in the event of an emergency that is related with the operation of power plants such as noise, dust, etc. 


\section{Conclusion}

The BLCP Power Plant has been implementing the principles of good governance and is in accordance with the law, by disseminating information through the media and through the dialogue to listen to the opinions and perceive the needs of the people. This is to contribute to the environmental management of the community around the power plant, as well as to remedy the impact caused by the operation of the power plant. However, the procedure must be in accordance with the regulations of the government agencies or state enterprises, which must prioritize the appropriateness and urgency of the problem or impact. As a result, people may view the solution as slow or unresponsive. So, the power plant should create a mutual understanding between them and the community about the operation of power plants, fuels, manufacturing technology, and, in particular, demonstrate safety measures and measures to prevent the impact on the environment for the public to be confident and feel reassured. The process of remedying people affected by the operation of the power plant should be clearly defined. In addition, people must know their rights and duties, be open mind and ready to learn from the media that is provided by the power plants to create the same understanding. This is to ensure that both parties can live together sustainably.

\section{References}

[1] Chompunth, C. (2017). Role of public participation in environmental impact assessment in Thailand, International Journal of GEOMATE, 12 (33), pp.109-113.

[2] Chompunth, C. and S. Chomphan. (2012). Evaluating Public Participation Process in Development Projects in Thailand: A Case Study of the Khao Hin Son Power Plant Project, American Journal of Applied Science, 9(3), pp. 865-873.

[3] Chaisomphob, T., J. Sanguanmanasak and K. Swangjang. (2004). Role of Public Participation in Planning Power Plant Project in Thailand, Thammasat International 9(1), pp. 67-73.

[4] Chesoh, S. (2011). Environmental Impact Assessment of Power Development Project: Lessons from Thailand Experiences, Asian Social Science, 7(9), pp 119-123. 
[5] Thailand Environmental Institute (2005). Environmental Governance: Indicators for Public Participation of the Year 2005. Bangkok, Thailand Environmental Institute.

[6] Chompunth, C. and S. Chomphan. (2012). Evaluating Public Participation Process in Development Projects in Thailand: A Case Study of the Khao Hin Son Power Plant Project, American Journal of Applied Science, 9(3), pp. 865-873.

[7] Abe, J., Brown, B., Ajao, E. A., \& Donkor, S. (2016). Local to regional polycentric levels of governance of the Guinea current large marine ecosystem. Environmental Development, 17(1), pp. 287-295.

[8] Paavola, J. (2007). Institutions and environmental governance: a reconceptualization. Ecological Economics, 63(1), 93-103.

[9] Tippett, J., B. Searle, C. Pahl-Wostl and Y. Rees. (2005). Social Learning in Public Participation in River Basin Management: Early Findings from Harmoni COP European Case Studies, Environmental Science and Policy, 8(3), pp. 287-299.

[10] Ogunlana, S. O., T. Yotsinsak and S. Yisa. (2001). An Assessment of People's Satisfaction with the Public Hearing on the Yadana Natural Gas Pipeline Project, Environmental Monitoring and Assessment, 72(2), pp. 207-225.

[11] Stampe, J.W. (2009). Lessons Learned from Environmental Impact Assessments: A Look at Two Widely Different Approaches - The USA and Thailand, The Journal of Transdisciplinary Environmental Studies, 8(1), pp. 1-7. 